\title{
Training System for Education Industry-An Outline
}

\author{
Sumit Prasad and Anupa Chaudhary
}

\begin{abstract}
Education has always been the grass root level, for building of personality trait of every individual. It is his learning's, which guides him, entire life for self-accomplishment and generates self-awareness for judgment in him. Education serves the purpose of broadening the horizon of individual for enhanced decision making, reasoning ability and an improved perceptional process. Education, which was earlier restricted to some part of the society, previously, has now become available for all. Since education is becoming easily accessible by the changing government policies, the quality of the education is education is still suffering, not in terms of what we teach, but the reason can be still we are teaching the same and in the same manner. Through this article author tries to give a new dimension to the professional education, and rethink upon the strategies we follows for the development of the students, by enhancing the quality of input and input variables.
\end{abstract}

Index Terms - Analysis of Training Need(AOTN), Evaluation, Job Performers, Standard of Performance (SOP).

\section{INTRODUCTION}

The purpose for the existence of any industry is to serve the mankind in a direct or an indirect manner, and so do the education industry is doing from its existence. It is continuously delivering a high quality product to the society for the maintenance of its fabric and its development. Over the period of time the education system we follow has proven itself enough competent to reach up-to the expectations of the society, contrary to this last few years are showing some downfall to meet up-to the expectation, resulting in unemployable students. This leads to rethink that where the actual problem is and to find out solution for that. There can be various reasons to the problem, so the author tries to make his contribution in the field by thinking upon the problem from a different point of view of training and development, and developing a system for identifying the problem associated.

\section{TRAINING SYSTEM FOR EDUCATION INDUSTRY}

Like any other industry, education industry is delivering a high quality of end products, for meeting the changing requirement and increasing the level of satisfaction of the society. The satisfaction that an end product can deliver to the end users is known as the quality of that product, and in terms of education industry the end product are the students and the

Manuscript received April 4, 2011; revised May 28, 2011.

Sumit Prasad is with the Amrapali Institute of Technology and Sciences, Haldwani, Uttarakhand 263139 India (phone: +919410579673; fax: None; e-mail: sumitprasad_coer85@yahoo.co.in).

Anupa Chaudhary is with the Amrapali Institute of Technology and Sciences, Haldwani, Uttarakhand 263139 India. (e-mail: anupa.chaudhary@gmail.com). end users are the recruiters. The purpose for any professional education is to bridge the gap between the requirement of the end users and the quality of the end products they are delivering, for increasing the probability of employability of the students. Development of the persona, attitude and the decision making ability of any student is dependent on the quality of the input variable. Over a period of time expectations of the recruiters have changed a lot, so as the need of the education, to evolve itself again to meet that pace of change. Hence resulting to think, once again, upon the input variable and try to enhance their quality. Unlike in any other industry, here also we are dealing with human resource, in terms of students and teachers. The quality of students is dependent on various input variables, one of which is the teacher. Hence there arises a need to develop a training system for the development of the teachers, so that the quality of the input provided by them, match the requirement of the recruiters.

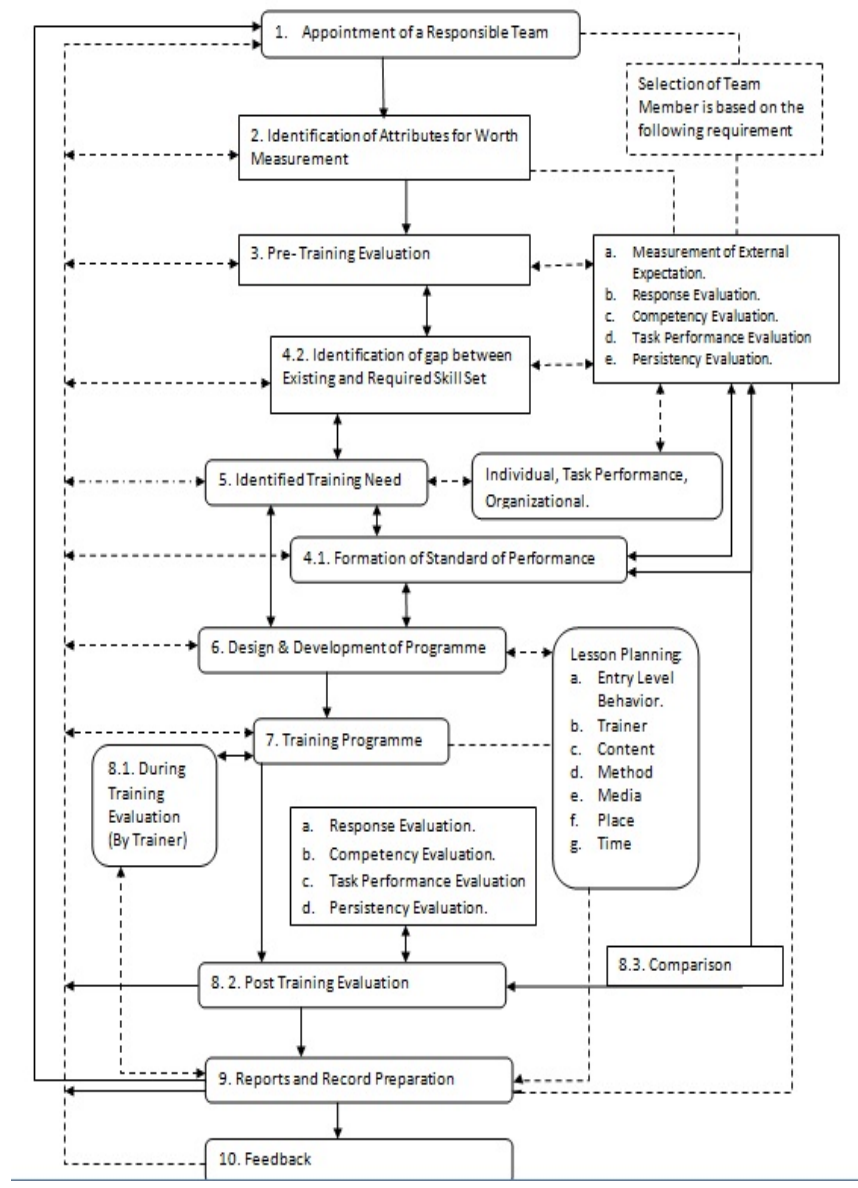

Fig. 1: Training System for Education Industry- An Outline

In the present scenario, teachers are more concern to the knowledge they are providing to their students, with the help of developed tools and techniques. Also to meet the pace of change, they are continuously updating and enhancing their knowledge by attending various training and development 
programs, by self identification of training needs. Here, where we are taking about the teachers, indulged in the noble profession of knowledge creation, are non-professionally self-identifying training needs for themselves. This effort of author is to develop a complete training system for teachers, so that they can directly attend the training and development programme, relevant to their current level of skill set and their learning behavior. The system for training is not a step by step approach; there exists an overlapping between its different phases. For the training system proposed please refer Fig. I.

\section{TRAINING SYSTEM EXPLAINED}

The proposed training system is explained under the following steps as:

1) Appointment of a responsible team: The process starts with the formation of a team, which will be whole and sole responsible for performing the duties involved. The team must be assigned with the authority and access to the data which is being required for performing the pre and post training evaluation. At the same time team will have the responsibility of presenting the data to the management for strengthening the training proposal. The formation of team is dependent on various factors, like maximum number of members in the team, who can be the member, duties and responsibility distribution among the members. Formation of team is done in synchronization with the kind of evaluation required. There is one more dimension to take care of, which is the measurement external expectation from the end products i.e. students, for which a team of placement officer can collect data from the recruiters. Therefore the team will be comprises of Head of Department, Placement officer and Training personal of the institution.

2) Identification of Attributes for Worth Measurement: The responsibility assigned to the team begins with the first step of identification of Competency Factors, i.e. what are attributes required to be present in the current job performers on the basis of which their skill set will be measured. While identification of the attributes the external expectation is also kept under consideration. The identification of attributes is a tailor made process and can vary intra-industry. The attributes identified, can be based upon Individual, Task Performance and Organizational Need. Some of them can be:

a) Technical (knowledge of the subject).

b) Awareness (horizontal expansion of knowledge).

1. Publications.

2. Memberships.

3. Projects.

4. Research Work.

c) iii)Behavioral.

d) Tools and Techniques.

e) Creativity.

f) Managerial Capabilities.

g) Experience.

3) Pre- Training Evaluation: Based on the attributes identified in the previous steps, a pre-training evaluation sheet is to be prepared. This data can also be prepared by the information recorded at the time of interview, and if the process is introducing the first time the entry level skill set can be assumed zero.

Teacher is a professional, who is assumed to be lying in the stage of self actualization need/Esteem need, based on the Maslow need hierarchy. He is quite competent enough to identify the hidden area (based on Johari Window) in himself to work upon and develop. University is the place where knowledge is disseminated and teacher holds the responsibility of knowledge creator, which reflects in the behavior of the students. Unlike any other manufacturing industry, the end product of the education industry i.e. students, have the capability to give the feedback on the quality of the input variable. Here the author is concerned with the capabilities of the teachers; hence the feedback here is related to the measurement of the quality of teachers. Based upon the above argument, three different dimensions are identified for the evaluation of the skill set of the teachers, as:

1) Evaluation by the team.

2) Evaluation by the end product (Students).

3) Self assessment.

For making this evaluation process more effective, some assumptions are required while designing the evaluation form:

1) Feedbacks of only those students are considered who are regular in class.

2) Feedback is not related to appraisal process.

3) Feedback must be unbiased.

4) This step is divided in two stages:

a) Formation of Standard of Performance (SOP): SOP's are the benchmarks, identified to carry the existing level of skills to the desired skills set of the potential trainees, which are formed by the team responsible for training. The quantitative value for an attribute will remains the same for all the potential trainers. Training is a tool to manage change in an effective manner, so that the present job performer can retain his present level of competency with the fast changing dimension and expectations of the job. The purpose to identify SOP is to forecast the level of skill set required to meet the gap between the existing level of competency and the required level of competency for performing the same task.

b) Identification of gap between Existing and Forecasted Skill Set: There is a need to quantify the gap between the forecasted and present skill set, so that training intervention can be provided to fill in that gap. The process of Gap Identification is done based on the Table No. I.

Name of Department:

To be filled by Team:

TABLE I: GAP IDENTIFICATION
\begin{tabular}{|l|c|l|c|l|l|l|}
\hline S.No & $\begin{array}{c}\text { Name of } \\
\text { Trainee }\end{array}$ & Attribute & $\begin{array}{c}\text { Topic for } \\
\text { Training }\end{array}$ & $\begin{array}{c}\text { Existing Skill } \\
\text { Set (a) }\end{array}$ & $\begin{array}{c}\text { Forecasted Skill } \\
\text { Set (SOP) }\end{array}$ & $\begin{array}{c}\text { Gap of } \\
\text { Skill Set } \\
(\mathbf{c}=\mathbf{b}-\mathbf{a})\end{array}$ \\
\hline 1 & ABC & XYZ & DEF & 2 & 3 & 1 \\
\hline & & & & & & \\
\hline
\end{tabular}

If ' $c$ ' is positive entity then the conclusion drawn is: Training is required.

If ' $c$ ' is negative or zero entity then the conclusion drawn is: Training is not required or need for establishing new 
forecasted skill set.

5) Identified Training Need: The end result of the above step is a compiled table depicting the requirement of the trainees. The next step is to set up a compiled status of trainees on the basis of training gap identified. The data collected above is represents the needs of an individual based upon the various attributes, after analysis, is re-tabulated based upon the total number of identified trainees on a single attributes, for categorizing them attribute wise. This can be done as (Please refer Table No. II):

TABLE II: TRAINING NEED IDENTIFICATION

\begin{tabular}{|c|c|c|c|c|c|}
\hline \multicolumn{6}{|c|}{ Name of the Attribute: } \\
\hline \multicolumn{6}{|c|}{ Topic for Training: } \\
\hline \multicolumn{6}{|c|}{ Nameofthe Trainer: } \\
\hline S.No. & Name of Department & Teaching Staff & $\begin{array}{l}\text { Supporting } \\
\text { Staff }\end{array}$ & Office Staff & 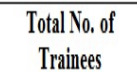 \\
\hline 1 & $A B C$ & $g$ & $\mathrm{H}$ & $i$ & $P=g+h+i$ \\
\hline 2 & $\mathrm{DEF}$ & j & K & 1 & $Q=j+k+1$ \\
\hline \multicolumn{2}{|c|}{ Total $\mathrm{N}_{0, \text { of }}$ Trainees } & $\mathrm{M}=\mathrm{g}+\mathrm{j}$ & $\mathrm{N}=\mathrm{h}+\mathrm{k}$ & $0=i+1$ & $\mathrm{M}+\mathrm{N}+0=\mathrm{P}+\mathrm{Q}$ \\
\hline
\end{tabular}

6) Design and Development of Programme: The next stage is to design and development of a training programme based on the identified training need. This process solves two purposes which are module designing and lesson planning. Lesson planning is the process of identifying the nature of the skill, which is to be imparted in the trainee, from tangible skill to abstract skill based on Long's Spectrum. Module designing is to identify the type of training intervention to be provided to meet the required behavior in job. Lesson planning is a subset for module designing, where module designing comprises of the entire component from need identification to evaluation and feed back, lesson planning is the strategy designed for actual learning event. Learning event is the stage where actual transformation of learning takes place through training programme.

Designing of training programme includes identification of trainer, content to be taught, method which links with the entry level behavior of the trainee, media, correct place where the actual learning will take place and the correct time for it. It is very necessary to consider all the above factors for designing a training programme, otherwise the learning intervention can become monotonous, or it can remain ineffective in imparting the skill in trainee.

7) Training Programme: This is the phase for implementing all the designed strategies. The plan so prepared based on various topics, which depicts the total number of trainees on every topic, is to be disseminated. A complete list of the trainings to be provided during the next year is to be prepared and displayed, representing the complete training schedule and identifying the trainers, trainees, venue and time.

8) Post Training Evaluation: This phase is divided into three stages-

a) During Training Evaluation: It becomes necessary to have a continuous follow-up during the training programme, for increasing its effectiveness. During this phase the trainer is required to continuously observe the behavior of the trainer during the training programme and note it down for further reference at the time of Post- Training evaluation. b) Post Training Evaluation: This is the phase of measuring the effectiveness of the training programme. It is the representation of, does the training programme actually meet the desired objectives, and if yes then to which extent. It also helps to strengthen the further proposal of training, or to take corrective measures if the training programme is not successful. Depending upon the time, when the evaluation takes place and its objective, this phase is divided into four stages:

1. Response Evaluation: This evaluation is done immediately after the actual training programme. Helping in measuring the response attitude of the trainees towards the effectiveness of the training programme and its benefits, trainer, content, method, media, place etc. It also helps in observing the response of the trainees towards the importance of the training intervention, i.e. do they believe that the training intervention will help them in their career enhancement or they take that as a part of their job duties.

2. Competency Evaluation: This is the measurement of the change, which takes place in skill as a result of training intervention. This test indicates that, whether the training gap is being filled or not. On time horizon scale, this test stands next to response evaluation, as this test is scheduled after some time of the training intervention.

3. Task Performance Evaluation: This test stand next to competency evaluation, on time horizon scale and measures the improvement in the actual job performance of the trainee. This evaluation helps in observing that, whether the trainee is able to implement his learning's in his on-the-job performance. This is done the observation of the team members.

4. Persistency Evaluation: This evaluation is the most neglected and most important evaluation of any training programme. The main motto of providing training is not only to improve the job performance of the trainee, but also to increase his job satisfaction which will energize him towards self-actualization need with a improved decision making power. This is the ultimate goal of any individual, and if any how the trainee can be able to link the training with his off-the-job performance, he will find a higher level of satisfaction, and his productivity will increase, and ultimately benefit to the individual and to the organization.

c) Comparison: After having the data of pre and post training evaluation, it becomes quite easier to compare the change between the pre- training and post- training behavior and skill set of the trainee. Comparison is a quantitative representation of the change that actually takes place after the training intervention.

9) Reports and Record Preparation: After the completion of the evaluation and comparison process, the next stage is to document all the results, so that the results can be displayed to the investors, indicating the return on investment made for conducting the training programme. It also helps in qualitatively indicating the effectiveness of the training and strengthens the upcoming training proposal. It also ensures that money which they are spending on training is not expenditure, but it is an investment, which will return with all its interest, and also helps the human resource asset to appreciate.

10) Feedback: The result so drawn is kept with the team, 
which will serve as a reference for the upcoming events and helps the training department to set benchmarks for them. The data collected above will also serve as a Pre-Training Evaluation data for the next training event and hence reduces the efforts to be put in for measuring it. It also depicts the areas where we need to need to improvise or modify if required.

\section{CONCLUSION}

The need for this paper is the continuous un-employability of the professional students, and identifying training as a potential source for its remedy. This paper's attempt of designing a proper training programme for teachers will help the education industry to canalize the training schedule for them, and assist them to develop their career with the help of training interventions. This will results in shouldering the responsibility of the AOTN for teacher in the hand of professionals, who can identify the correct training need, and provide the training desired by the teachers.

The outcome of this practice is a pre planned and tailor made training intervention, designed specifically for the teachers, considering their requirement in mind. The training so provided will enhance the skill set of the teachers, on various attributes, so that the common error of training overlapping / skill overlapping can be rectified.

\section{REFERENCES}

[1] Prasad, S., Chaudhary, A., \& Prasad, S., Training System- A Perspective. IJIMT, Vol. 2, No. 1, February, 2011, ISSN: 2010-0248, pp.69-72.

[2] Chaudhary, A., Prasad, S., Human Resource Financial Management, IJTEF, Vol. 1, No. 4, Dec, 2010, 2010-023X, pp. 342-344.
[3] Chaudhary, A., Prasad, S., Training for Development of Professional Education, IJIMT, Vol. 2, No. 2, April, 2011, ISSN: 2010-0248, pp. 162-165.

[4] Pulla Rao, D. Development of teachers education in India: an historical perspective. Indian Journal of Training and Development, Vol.39, No.3 (2009, July-Sep).

[5] Joshi, P. Total quality management implication for universities. Published in Ripples- Quarterly news letter of Kumaun University Nainital (Uttrakhand), India (2009, Nov).

[6] Rajasingh, S., \& Rajasekaran, B. Perceptual difference between industry and academic leaders. Indian Journal of Training and Development, Vol.39, No.3 (2009, July-Sep).

[7] Trueloves, S., "Training for Development- A Handbook," 1st ed., Ed. New Delhi: Infinity books, 2000.

[8] Anderson, A. H., "Training in Practice", 1st ed., Ed. New Delhi Infinity books, 2000.

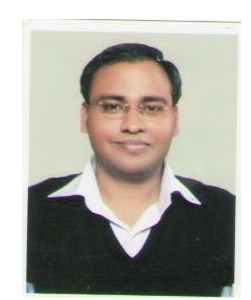

Sumit Prasad was born in Uttrakhand India, in the month of July' 1985. Sumit has acquired Masters in Business Administration with specialization in human resource management and marketing from Kumaun Univerity, Nainital- India in the year 2009. $\mathrm{He}$ is an undergraduate of Bachelor of Technology in mechanical engineering from Uttar Pradesh Technical Univeristy, India, in the year 2006.

$\mathrm{He}$ is working as an Assistant Professor in Amrapali Institute of Technology and Sciences, and sharing his knowledge with the coming generation in the field of engineering and management. He has also contributing as an honorary assistant professor and visiting fellow to an open business college situated in England. He is not limited to his classroom instead he wrote various articles which are published in international journals and conferences as: Prasad, S., Chaudhary, A., \& Prasad, S., Training System- A Perspective. IJIMT, Vol. 2, No. 1, February, 2011, ISSN: 2010-0248, pp.69-72; Chaudhary, A., Prasad, S., Human Resource Financial Management, IJTEF, Vol. 1, No. 4, Dec, 2010, 2010-023X, pp. 342-344; Chaudhary, A., Prasad, S., Training for Development of Professional Education, IJIMT, Vol. 2, No. 2, April, 2011, ISSN: 2010-0248, pp. 162-165. His research interest areas include training and development, change management, knowledge management.

Er. Prasad holds a membership of IEDRC and IACSIT.

Anupa Chaudhary, photograph and biography not available at the time ofpublishing 